\section{European Brewery Convention}

Report of the Barley Committee: Trials, 1961. Pp. 136. (London: Institute of Brewing, 1963.)

\begin{abstract}
7CHIS twelfth report of the series compares the agricultural and malting performances of various new barley varieties in fifteen European countries. In addition to details of sowing, ripeness, yields, quality characteristics such as nitrogen-content, grain size and dormancy, the volume contains a wealth of tabulated data on the lay-out of the individual trials, their location, soil analysis, fertilizer treatment, field observations such as those relating to disease resistance, meteorological data and statistical evaluation of yields. Moreover, samples of the barleys were converted into malts by small-scale methods and, here also, the newcomer to this field will perhaps be surprised both by the variation in the results and by the multitude of malt properties which have to be brought into view to provide an adequate comparison.

It will be clear that this is a specialized publication of particular importance to those concerned to see that with this quantitatively and economically outstanding crop the varieties grown shall best meet the rather different needs of the farmer and the maltster. It has, however, a wider lesson to teach by revealing how complex a problem is posed by this seemingly simple objective. Thus not only are the barleys subject to almost unavoidable variations in methods of cultivation and uncontrollable differences of weather, the malts also vary widely. The latter circumstance is in part due to the fact that different regions often prefer malts of quite different character, but is also the result of malting plants apparently giving different qualities of product even when much care is taken to standardize the procedure employed. These considera. tions are additional to more familiar ones such as the adequate botanical description, identification and stability of the new varieties. The present volume, therefore, both summarizes clearly the results of a phenomenal number of hours of endeavour and provides a valuable guide to those who may be concerned with similar evaluations of other crops on a wide geographical basis. A. H. CooK
\end{abstract}

\section{Advances in Astronautical Propulsion}

Proceedings of a Seminar held in Milan by Istituto Lombardo Accademia di Scienze o Lettere in collaboration with the Advisory Group for Aeronautical Research and Development of Nato, 8-12 September 1960. Edited by Corrado Casci. (International Series of Monographs in Aeronautics and Astronautics. Division 9: Symposia, Vol. 11.) Pp. xxvii + 366. (London and New York: Pergamon Press; Milan: Editrice Politecnica Tamburini, 1962.) 100s.

7 HE papers which compose this volume are concerned with most aspects of astronautical propulsion and a few other closely related subjects. The book begins with a useful introduction to the various methods of electrical propulsion, by the late Theodore von Kármán. Then comes a fine survey of the mechanics of space propulsion by L. Crocco (in Italian), covering the dynamics of highand low-thrust systems and the proporties of transfer orbits. There follow four contributions on conventional rocket propulsion, including a passionate plea for solid fuels from J. Buchanan, and a pleasing discourse on liquid-fuel rockets by $\mathrm{A}$. $\mathrm{O}$. Tischler. Nuclear rockets form the subject of two papers, a practical survey of fission rockets by $R$. W. Bussard, and a forward-looking review by E. Sänger, covering such topies as photonic fission rockets and intermittent water plasma fusion rockets. Other papers deal with magnetohydrodynamics and power generation in space. The dynamical and heating problems of atmospheric re-entry are admirably discussed in three papers by A. Ferri, L. Broglio and P. A. Libby. Finally, H. L. Dryden outlines some of the future United States plans and also "dips into the future far as human eye can see".
The papers (though not all well written) together constitute an excellent review of the subject. But the book is marred by printing errors so numerous and glaring that they often distract the reader's attention and sometimes obscure the meaning. D. G. KING-HeLE

Thermodynamic Properties of Helium to $50,000^{\circ} \mathrm{K}$ By Wilbert J. Lick and Howard W. Emmons. Pp. 122 (including charts). (Cambridge, Mass: Harvard University Press; London: Oxford University Press, 1962.) 24s.; 2.95 dollars.

THE authors give an excellent and precise account of the methods used in the preparation of these tables, although the preceding introduction is a discouragingly vague attempt to justify their existence. In contrast to many other similar compilations, it is indeed welcome to find an extremely graphic physical discussion of the type of atomic model and particle interactions assumed. in the analysis. The partition functions for electronic excitation and ionization are based on Unsölds treatment, and thus allow for a density-dependent cut-off of levels and reduction in ionization potential due to particle interactions. The justification and validity of this approach is discussed clearly and at length. There are 108 pages of thermodynamic data-including sound speed-for equilibrium mixtures from $8,000^{\circ}$ to $49,800^{\circ} \mathrm{K}$ and from $10^{-4}$ to $10^{3} \mathrm{~atm}$., listed in steps of $200^{\circ} \mathrm{K}$ for each tenfold pressure increment. The chemical species considered are $\mathrm{He}, \mathrm{He}^{+}, \mathrm{He}^{++}$, and $e$; the molar constituents of these are similarly tabulated. The data is also conveniently presented in the form of two splendidly large and clear Mollier charts. This will be welcome to those concerned with the use of helium in high-enthalpy electrically driven shock tubes, although an order extension in pressure would be useful in this respect. The extreme range covered will be more than adequate for those interested in its use in plasma-are and space propulsion facilities.

IAN R. HuRle

\section{Plant Hairs}

By Prof. J. C. Th. Uphof. Die Verbreitung der Haartypen in den Natürlichen Verwandtschaftsgruppen. Von Dr. Karl Hummel und Karin Staesche. (Handbuch der Pflanzenanatomie, Band IV, Teil 5). Pp. xi+292+5 plates. (Berlin-Nikolassee: Gebrüder Borntraeger, 1962.) 96 D.M.

THE long article by Uphof looks like a general essay on hairs and emergences, but is really a pure compila. tion. The author, on the evidence of his own bibliography, has not been personally active in this field of research, and does not deal with the plants themselves, but only with the literature concerning them. Furthermore, his scale of values is antiquarian rather than botanical. Nothing can disguise the intrinsic sterility of such a treatment. The botany expounded here is one in which iodine is the principal histological stain, and in which the electron microscopy of the cotton fibre is firmly subordinated to the "faint reticulation" which appeared on staining with Congo red in 1925.

The shorter contribution by Hummel and Staesche is a statement of the distribution of the principal hairtypes (unicellular, uniseriate, stellate, etc.) among the angiosperms. The only conceivable objection to it is that the material might just as woll have been tabulated in a fraction of the space.

A.t this price the purchaser is entitled to a professional standard of book-production. He does not get it. The English text reads like a bad translation, misprints abound, and Hummel repeats both his own statements and Uphof's to an extent which borders on the farcical. In all, this is a serviceable classified guide to a scattered literature, giving enough detail to obviate in many cases all need for reference to the originals. From every other point of view, it represents a lost opportunity.

K. J. DORMER 